\title{
Versification at the 2014 ASEEES Convention (November 2014, San Antonio, Texas, USA)
}

\author{
Barry P. Scherr
}

The Association for Slavic, East European and Eurasian Studies (ASEEES; formerly known as the American Association for the Advancement of Slavic Studies, or AAASS) is the largest organization in the United States for scholars whose research involves Eastern Europe and the countries that formerly were part of the Soviet Union. A wide variety of disciplines are represented in the organization: historians, political scientists, literary scholars, linguists, film scholars, sociologists, anthropologists, economists, geographers, etc. Typically, more than 2000 people attend the annual conventon, which is held in various cities throughout North America. During the 1980s and 1990s nearly every year saw at least one panel (out of the several hundred at each convention) devoted to versification. However, with the retirement of several American verse scholars it became increasingly difficult to hold such panels on a regular basis, and for the several years immediately prior to 2014 there had not been any that focused on verse theory.

In 2014 several scholars from Eastern Europe and Russia agreed to attend the ASEEES conference, which allowed for the organization of two panels. At the first of these, "Versification in the 21st Century" Tatyana Vladimirovna Skulacheva spoke on "What's New in Russian Verse Study." Three developments were highlighted in her talk. First, she referred to what she termed a "new wave" in the study of non-classical verse. If scholars such as M. L. Gasparov carried out the fundamental work in defining and initially analysing these metres, then scholars today are engaged in the tasks of looking at recent developments in their usage and finding new approaches to analysing their essential features. Second, she referred to the use of computer-aided analysis in verse studies. Computers have for some time been used to look at matters such as phonetics, but now the attention of researchers is turning to applying the power of computer analysis to additional aspects of verse study. For many years individual researchers have manually (and painstakingly) noted the metres and rhythm of individual poems; computers offer the promise of dealing with vast bodies of verse and providing data on a scale not previously possible. Much of her talk was devoted to the recent application of brain studies to the analysis of poetic texts. After initially studying and determining the most basic components of verse across a number of languages, this field has now started to 
explore additional problems. Among these, one of the key issues involves the varying lengths of pauses between words. Research has shown that the closer syntactic ties (and thus the shorter pauses) occur at the end and at the beginning of a verse line, whereas the looser ties are to be found in the middle. At the end of her talk she took note of the wide range of specialists - linguists, statisticians, neurophysiologists - who are joining forces in an effort to gain a more comprehensive knowledge of verse.

The paper by Robert Ibrahim-Kolár and Petr Plecháč, both from the Institute of Czech Literature, Czech Academy of Sciences, was titled "How to Compile and Use a Verse Corpus: The Example of Czech" and was presented by Petr Plecháč. The Corpus of Czech Verse currently contains nearly 80,000 poems with more than 2,5 million lines of poetry. A computer program has automatically provided information about the basic (non-inflected) form of each word in the corpus as well as about its grammatical categories. In their paper, the two scholars focused on two aspects of computer analysis: the phonetic and the metrical. The phonetic analysis in some ways has proved to be the easier of the two, with the computer able to use a series of rules to provide a phonetic description that is accurate in all but a relatively small number of instances, when it is necessary to resort to a manually built dictionary. Examination of a random sample shows that the error rate is quite small, on the order of nine mistakes per 10,000 sounds. The computer-assisted metrical analysis, by contrast, for now is essentially "semi-automatic," with manual checking called for unless a series of conditions has been met. The combined manual and automatic approach to identifying metres has again resulted in a very low error rate (about .03\%). The latter portion of the paper briefly described several other features of the work that has been done to date, including the creation of databases for Czech metres and rhymes, as well as a program that searches for keywords according to a set of criteria that can be described by the researcher.

Unfortunately, Oleg Mikhailovich Anshakov, who was scheduled to speak on "Computer-Aided Verse Study," was not able to attend the conference; however, a brief summary of his talk was provided by Tatyana Skulacheva at the conclusion of the second panel.

That panel, "Russian Versification Studies in Metre and Rhythm," opened with a paper by Mihhail Lotman, of Tallinn and Tartu Universities: "Metre: A Template or (Probablistic) Measure" which in his absence was read by Barry Scherr. The paper consisted of two sections. The first dealt with the fundamental problem of defining metre. He noted that metre is often an adopted form, whose origins are not clear. One way of understanding metre is to regard it as an abstract structure, which is then realised differently in various verse traditions. For instance, the metrical "template" of the hexameter can serve as 
the basis for very different hexametrical forms: quantitative-syllabic, accentual-syllabic, etc. Metre is often realised through rhythm, but it can also be associated with other kinds of cognitive structures, including grammar, syntax, and semantics. The second part of the paper involved an approach to texts that appears to be metrical but cannot be associated with a particular template. The instance examined in this paper was Pushkin's oft-studied but never satisfactorily categorised "West Slavic Songs" («Песни западных славян»). Previous studies have focused on analysing the distribution of stresses to try to fit the poem into a particular metre, usually anapestic or trochaic, but these have all failed to explain a significant number of lines. M. L. Gasparov comes closest, but in claiming that the "West Slavic Songs" are written in the rather amorphous 3-stress taktovik he accounts for only about $90 \%$ of the lines. Lotman proposes a quite different, probabilistic approach, in which the key factors turn out to be (1) a strong tendency toward lines of 10 syllables and (2) a regularity in the distribution of word boundaries, which is independent of the distribution of stresses.

Aleksandr Mikhailovich Levashov presented a talk on "The Russian Dolnik of the 20th and 21st Centuries," which he had co-authored with by Sergei Evgenievich Liapin. The authors pointed out that dol'nik verse not only remained popular during the latter part of the 20th century and into the 21st, but that its features had evolved, requiring new approaches to its analysis. A major focus of their paper was the verse of Joseph Brodsky, which researchers have often had difficulty in classifying, given the irregularities (such as large clusters of unstressed syllables) that categorise many lines. The approach of Levashov and Liapin is in a way probabilistic as well, searching for various features that allow them to find strong tendencies in verse that at first glance seem resistant to conventional analysis. Thus they classify a group of poems by Brodsky as consisting of 6-stress dol'niki so long as at least $75 \%$ of the lines contain six ictuses, and they offer statistical analyses to highlight certain features: the division of these lines into two somewhat independent hemistichs, the manner in which weak and strong syntactic links emphasise the metrical structure of the lines, and the differences between the two hemistichs. Their analyses show that the seeming irregularities of Brodsky's verse do not, in the final analysis, prevent their belonging to the category of dol'nik verse.

Finally, Stanislav Shvabrin (University of North Carolina, USA) in "Quantifiable Metaphysics: Nabokov and 'Non-Classical' Prosody," also deals with dol'nik verse, albeit in a very different way. In his own original poetry Nabokov largely avoided the non-classical verse forms that had come into fashion at the beginning of the modern era (and which Nabokov seems to have associated with writers who were politically to the left). However, the 
opening paragraph of Chapter 18 in Nabokov's Invitation to a Beheading («Пиглашение на казнь»), includes quotations from the beginning of the first line in Tiutchev's poem "Last Love" («Последняя любовь») and the end of the second line (in the English translation, which was done by Nabokov's son in collaboration with the author, these lines are quoted in their entirety). That second line is the first of five in this 12-line poem that deviates from the iambic tetrameter of the other seven lines and is written in what today would be called dol'nik verse. Shvabrin noted that Nabokov preferred Sergei Bobrov's term pauznik and used it to apply to a broader range of verse forms in which the number of weak syllables between ictuses is variable. The reference to Tiutchev's innovative verse at this key moment in the novel, where the hero clearly senses his own doom, shows that Nabokov saw this form, with its interruption of orderly expectation, as possessing not just a literary or political but also a "metaphysical" significance. 